\title{
Boas práticas de manipulação em serviços de alimentação no município de Santa Rosa - RS
}

\section{Good practices for handling in food services in the}

municipality of Santa Rosa - RS

Andressa Silva Lachno ${ }^{1}$

Melissa dos Santos Oliveira²

Paula Michele Abentroth Klaic ${ }^{3}$

Gislaine Hermanns ${ }^{4}$
RECEBIDO EM 11/11/2020

ACEITO EM 08/09/2021

\begin{abstract}
RESUMO
A segurança higiênico-sanitária dos locais e dos produtos oferecidos nos estabelecimentos alimentícios é uma preocupação dos órgãos públicos. A fim de garantir a segurança dos alimentos aos consumidores, no Rio Grande do Sul, em 2009, a Secretaria Estadual de Saúde (SES/RS) desenvolveu um checklist para verificação da adoção das boas práticas em serviços de alimentação. Assim, o objetivo deste estudo foi verificar a adoção e adequação das BPM - Boas Práticas de Manipulação - em estabelecimentos manipuladores de alimentos, no município de Santa Rosa - RS. Foi realizado um estudo transversal de caráter descritivo e exploratório, em que foram levantadas as conformidades e não conformidades, em relação às BPM de alimentos, nesses locais. A coleta de dados se deu por meio da aplicação do checklist anexo à Portaria Nº 078/2009 da SES/RS. Foram avaliados doze estabelecimentos, classificados como serviços
\end{abstract}

\footnotetext{
1 Especialista pelo Instituto Federal Farroupilha, IFFar, Campus Santa Rosa, Rio Grande do Sul, Brasil. andressalachno23@gmail.com - https://orcid.org/0000-0002-4639-4768

2 Professora Doutora no Instituto Federal Farroupilha, IFFar, Campus Santo Augusto, Rio Grande do Sul, Brasil. melissa.oliveira@iffarroupilha.edu.br - https://orcid.org/0000-0002-7084-3674

3 Professora Doutora no Instituto Federal Farroupilha, IFFar, Campus Santa Rosa, Rio Grande do Sul, Brasil. paula.klaic@iffarroupilha.edu.br - https://orcid.org/0000-0002-4350-4597

4 Professora Doutora no Instituto Federal Farroupilha, IFFar, Campus Santa Rosa, Rio Grande do Sul, Brasil. gislaine.hermanns@iffarroupilha.edu.br - https://orcid.org/0000-0002-7918-3895
} 
de alimentação, entre os quais sete restaurantes, três pizzarias e dois bares, no primeiro semestre de 2019. Apenas 56,8\% dos itens analisados se mostraram em conformidade com a legislação. O maior percentual de conformidades observado (90,5\%) estava relacionado ao controle integrado de pragas; o menor (6,3\%), ao item "documentação e registros". Os resultados do estudo apontaram para um alto percentual de BPM não atendidas, o que pode possibilitar riscos à saúde dos consumidores. O não atendimento às normas estabelecidas na legislação contribui para uma baixa qualidade higiênico-sanitária dos alimentos produzidos, sugerindo-se, portanto, que os estabelecimentos invistam em treinamentos e medidas para a correção dessas não conformidades.

PALAVRAS-CHAVE: aspectos higiênico-sanitários; restaurantes comerciais; legislação.

\section{ABSTRACT}

The hygienic and sanitary safety of places and products offered in food establishments is a concern of public agencies. In order to ensure food safety to consumers, in 2009, the State Health Department of Rio Grande do Sul (DHS/RS) developed a checklist to verify the adoption of good practices in food services. The objective of this study was to verify the adoption and adequacy of GHP - Good Handling Practices at establishments food handlers in the city of Santa Rosa - RS. A cross-sectional descriptive and exploratory study was carried out, where conformity and non-conformities were raised in relation to GHP in these places. Data collection took place through the application of the checklist attached to Ordinance No 078/2009 of DHS/RS. In the first half of 2019, twelve establishments were evaluated, classified as food services, seven restaurants, three pizzerias and two bars. Only $56.8 \%$ of the items analyzed were in compliance with the legislation. The highest percentage of compliance observed (90.5\%) was related to integrated pest control. The lowest percentage of compliance observed (6.3\%) was in relation to the item of documentation and records. The results of this study pointed to a high percentage of items not attended to in relation to GHP, which can lead to risks to the health of consumers. Failure to comply with the standards established in the legislation contributes to a low hygienic-sanitary quality of the food produced, suggesting that establishments should invest in training and measures to correct these non-conformities.

KEYWORDS: hygienic-sanitary aspects; commercial restaurants; legislation. 


\section{Introdução}

A partir da segunda metade do século XX, ocorreram grandes transformações na sociedade brasileira devido ao desenvolvimento industrial, com destaque para mudanças relacionadas aos hábitos sociais e ao padrão de consumo alimentar (AKUTSU et al., 2005), o que influi na escolha, pelo indivíduo, do seu local de alimentação. A segurança higiênico-sanitária dos locais e dos produtos oferecidos nos estabelecimentos alimentícios é uma preocupação dos órgãos públicos e demanda rigoroso controle sanitário dos alimentos (SANTOS; RANGEL; AZEREDO, 2010), constituindo-se em uma das principais causas de aumento dos índices de morbidade nos países da América Latina e do Caribe (AKUTSU et al., 2005).

Essa preocupação está relacionada, principalmente, com as Doenças Transmitidas por Alimentos (DTA). Muitas podem ser as fontes de transmissão de doenças por alimentos contaminados, sendo algumas delas, de grande importância a falta de higiene por parte dos manipuladores de alimentos, bem como as condições de higiene deficitárias durante o armazenamento e a conservação dos alimentos. Um dos aspectos que dificulta um trabalho adequado, dentro de condições higiênico-sanitárias satisfatórias é a estrutura física dos estabelecimentos, que muitas vezes encontra-se em mau estado de conservação (SILVA, 2005; AKUTSU et al., 2005).

Segundo Oliveira et al. (2010) existem aproximadamente 250 tipos de DTA, muitas das quais são causadas por microrganismos patogênicos, responsáveis por graves problemas de saúde pública e expressivas perdas econômicas, o que tem preocupado as autoridades sanitárias nos últimos anos. Para que os alimentos sejam considerados seguros e confiáveis, uma das alternativas é a adoção de ferramentas que ajudem a prevenir e manter os alimentos dentro de um padrão de qualidade sanitária. Dentre elas, destaca-se o programa de Boas Práticas de Fabricação (BPF) (BRASIL, 2004). 
A fim de garantir a segurança dos alimentos aos consumidores, a Agência Nacional de Vigilância Sanitária (Anvisa), por meio das Resoluções RDC 275/2002 e RDC 216/2004, criou um programa que deve ser adotado por todas as indústrias de alimentos e serviços de alimentação no país, centrado nas BPF. Segundo a Resolução RDC 216/2004, as BPF são procedimentos que devem ser adotados por serviços de alimentação a fim de garantir a qualidade higiênico-sanitária e a conformidade dos alimentos com a legislação sanitária brasileira (BRASIL, 2004).

As boas práticas, citadas pela legislação vigente, foram denominadas como BPF, quando voltadas a indústrias; já para serviços de alimentação, em que não há fabricação de alimentos, mas, sim, manipulação, a nomenclatura a ser adotada é Boas Práticas de Manipulação (BPM). As BPM se caracterizam como um conjunto de medidas adotadas pelos estabelecimentos que manipulam alimentos. Têm como objetivo garantir um padrão de qualidade dos alimentos, estabelecido por condições de armazenamento, condições estruturais das edificações, equipamentos, limpeza e sanitização, controle de pragas e higiene pessoal (BLANGER; NUNES; SANT'ANNA, 2017). Em consonância com essas legislações, a Secretaria de Saúde do Estado do Rio Grande do Sul (SES/RS) aprovou, no ano de 2009, a Portaria 78/2009, que amplia a lista de estabelecimentos da RDC 216/2004 da Anvisa e traz uma lista de verificação de conformidades (checklist) em relação às BMP para serviços de alimentação do estado (RIO GRANDE DO SUL, 2009).

Os serviços de alimentação comercial, como bares e restaurantes, têm como objetivo principal a obtenção de lucro com a venda de refeições. Segundo o Instituto Food Service Brasil (IFB), na última década o setor de food service brasileiro movimentou mais de 170 bilhões de reais por ano, tendo, apesar da crise, aumento de 3,9\% das receitas em 2017, em comparação com o mesmo 
período do ano anterior. Isso evidencia que, mesmo com a retração da economia, a população brasileira manteve o hábito de se alimentar fora de casa.

As BPM são as principais ferramentas de garantia da qualidade de um alimento, quanto a prevenção de contaminações biológicas, físicas e químicas, desde a matéria-prima até o produto final (GERMANO; GERMANO, 2011). Com base no exposto, o objetivo deste estudo foi verificar a adoção e adequação das BPM em serviços de alimentação no município de Santa Rosa, no noroeste do estado do Rio Grande do Sul, utilizando-se o checklist proposto pela Portaria 78/2009 da SES/RS.

\section{Materiais e Métodos}

Este estudo foi realizado de forma transversal, tendo caráter descritivo e exploratório, e levantou conformidades e não conformidades em relação às BPM em serviços de alimentação de Santa Rosa (RS). A coleta de dados se deu pela aplicação do checklist anexo à Portaria 078/2009 SES/RS.

A seleção dos estabelecimentos foi realizada de forma aleatória, totalizando doze empresas, entre as quais sete restaurantes, três pizzarias e dois bares. Durante as visitas, o checklist foi preenchido pela pesquisadora em face das suas observações no próprio local, complementadas por informações fornecidas por colaboradores do estabelecimento.

O checklist utilizado constou de 149 itens, divididos em doze blocos de questões relacionadas a vários aspectos estabelecidos pela legislação: edificações, instalações, equipamentos, móveis e utensílios; higienização de instalações, equipamentos, móveis e utensílios; controle integrado de pragas; abastecimento de água; manejo de resíduos; manipuladores; matérias-primas, ingredientes e embalagens; preparação do alimento; armazenamento e transporte do alimento preparado; exposição ao consumo do alimento preparado; documentação e registro; e responsabilidade. As opções de respostas para 
o preenchimento do checklist foram: "Conforme" (C) quando houve atendimento ao item observado; "Não Conforme" (NC) quando o estabelecimento apresentou não conformidade quanto ao item observado; "Não Aplicável" (NA) quando o item foi considerado não pertinente ao local pesquisado. As questões tendo como resposta a opção NA não foram contabilizadas nos cálculos dos percentuais de conformidade e não conformidades.

A classificação dos estabelecimentos seguiu aquela proposta pela Resolução RDC 275, de 21 de outubro de 2002 - que dispõe sobre o Regulamento Técnico de Boas Práticas para Estabelecimentos Produtores/Industrializadores de Alimentos (BRASIL, 2002) -, já que as legislações específicas para o segmento de serviços de alimentação não trazem tal descrição. A classificação dos estabelecimentos, segundo a legislação, é dada em grupos, de acordo com o percentual de conformidades atingidas: Grupo 1 - 76 a 100\% de atendimento dos itens; Grupo 2 - 51 a 75\% de atendimento dos itens; Grupo 3 - 0 a 50\% de atendimento dos itens.

A análise dos dados foi realizada em cada um dos doze blocos de questões, conforme apresentado no próprio checklist, e os resultados expressos em percentuais.

\section{Resultados e Discussões}

O checklist foi aplicado em doze estabelecimentos classificados como serviços de alimentação, no município de Santa Rosa, no primeiro semestre de 2019. Desses, sete se caracterizavam como restaurantes (58,3\%), três como pizzarias (25\%), e dois como bares (16,7\%). Foram analisados doze blocos de questões, com um total de 149 itens, relacionados a diversos aspectos da produção segura de alimentos estabelecidos pela legislação. A Tabela 1 apresenta o número de manipuladores de cada estabelecimento alimentício, 
variando de dois até, no máximo, dez manipuladores. Destaca-se que apenas um restaurante demonstrou dispor de responsável técnico.

TABELA 1 - Número de manipuladores por estabelecimento.

\begin{tabular}{|c|c|c|}
\hline Estabelecimento & $\mathrm{N}^{\circ}$ de manipuladores & Responsável \\
\hline \multicolumn{3}{|l|}{ Bares } \\
\hline 1 & 2 & Não possui \\
\hline 2 & 4 & Não possui \\
\hline \multicolumn{3}{|l|}{ Pizzarias } \\
\hline 1 & 2 & Não possui \\
\hline 2 & 8 & Não possui \\
\hline 3 & 4 & Não possui \\
\hline \multicolumn{3}{|l|}{ Restaurantes } \\
\hline 1 & 5 & Não possui \\
\hline 2 & 5 & Nutricionista \\
\hline 3 & 4 & Não possui \\
\hline 4 & 4 & Não possui \\
\hline 5 & 3 & Não possui \\
\hline 6 & 4 & Não possui \\
\hline 7 & 10 & Não possui \\
\hline
\end{tabular}

Fonte: elaborada pelo próprio autor.

A Tabela 2 apresenta os percentuais de conformidades, não conformidades e questões não aplicáveis, de acordo com o bloco de avaliação dado pelo checklist adotado. Destaca-se que o percentual mais alto, com 90,5\% de conformidades, foi identificado no bloco de avaliação referente ao controle integrado de pragas; já o menor, no bloco de documentação e registro, com apenas 6,3\% de conformidades. Apenas alguns restaurantes apresentaram documentação nessa categoria. Diversos autores apontam que a maioria das não adequações está relacionada a problemas estruturais e de registros de documentação (BLANGER; NUNES; SANT'ANNA, 2017; GIRELLI et al., 2015), possivelmente pela não exigência de responsável técnico (RT) para liberação de alvará sanitário. 
TABELA 2 - Percentual de itens em conformidade, não conformidade e não aplicabilidade.

\begin{tabular}{lcccc}
\multicolumn{1}{c}{ Itens avaliados } & $\begin{array}{c}N^{0} \text { de } \\
\text { questões }\end{array}$ & C $^{*}$ & $\%$ NC & NA \\
\hline $\begin{array}{l}\text { Bloco 1 - Edificação, Instalações, Equipamentos, } \\
\text { Móveis e Utensílios }\end{array}$ & 34 & 55,4 & 37,7 & 6,9 \\
\hline $\begin{array}{l}\text { Bloco 2 - Higienização de Instalações, } \\
\text { Equipamentos, Móveis e Utensílios }\end{array}$ & 17 & 46,6 & 40,7 & 12,7 \\
\hline Bloco 3 - Controle Integrado de Pragas & 7 & 90,5 & 9,5 & 0 \\
\hline Bloco 4 - Abastecimento de Água & 9 & 61,1 & 12 & 26,9 \\
\hline Bloco 5 - Manejo de Resíduos & 3 & 61,1 & 38,9 & 0 \\
\hline Bloco 6 - Manipuladores & 15 & 44,4 & 48,9 & 6,7 \\
\hline $\begin{array}{l}\text { Bloco 7 - Matérias-primas, Ingredientes e } \\
\text { Embalagens }\end{array}$ & 12 & 64,6 & 35,4 & 0 \\
\hline Bloco 8 - Preparação do Alimento & 26 & 30,1 & 40,7 & 29,2 \\
\hline $\begin{array}{l}\text { Bloco 9 - Armazenamento e Transporte do } \\
\text { Alimento preparado }\end{array}$ & 6 & 25 & 11,1 & 63,9 \\
\hline $\begin{array}{l}\text { Bloco 10 - Exposição ao Consumo do Alimento } \\
\text { Preparado }\end{array}$ & 9 & 64,8 & 14,8 & 20,4 \\
\hline Bloco 11 - Documentação e Registro & 4 & 6,3 & 93,8 & 0 \\
\hline Bloco 12 - Responsabilidade & 7 & 30,6 & 69,4 & 0 \\
\hline
\end{tabular}

${ }^{* *} \mathrm{C}=$ conforme; $\mathrm{NC}=$ não conforme; $\mathrm{NA}$ = não aplicável ${ }^{*}$

Fonte: elaborada pelo próprio autor.

Quando as questões avaliadas como NA foram desconsideradas no cálculo percentual de conformidades, apenas $56,8 \%$ dos itens foram avaliados como conformes. Esse dado demonstra uma queda nos quesitos conformes de uma maneira geral, quando comparado a uma pesquisa realizada no mesmo município no ano de 2006, segundo a qual 64\% dos itens estavam em conformidade com a legislação vigente (POERNER et al., 2009). Os percentuais de conformidades, atingidos de acordo com o tipo de estabelecimento, excluídos os itens não aplicáveis, são apresentados na Figura 1. 
FIGURA 1 - Comparação entre médias de percentuais de conformidades entre os tipos de estabelecimentos.

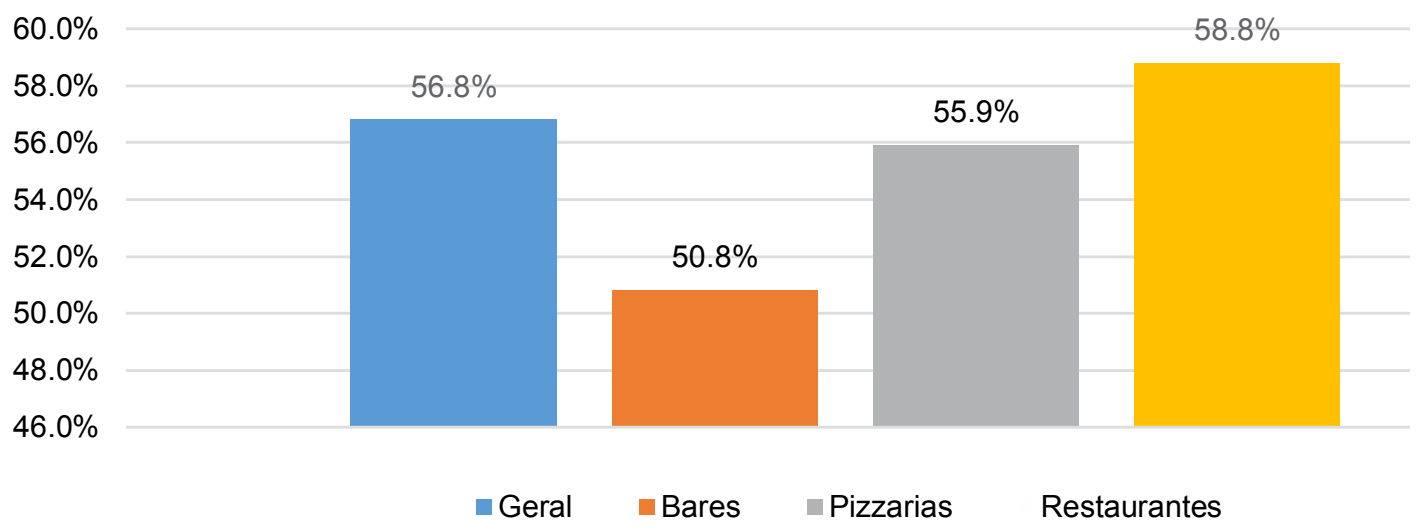

Fonte: elaborada pelo próprio autor.

Atualmente, na legislação não há um percentual de adequação mínimo para um estabelecimento que produz e comercializa refeições ser considerado seguro (BLANGER; NUNES; SANT'ANNA, 2017). Dessa forma, optou-se por utilizar as classificações de estabelecimentos produtores/industrializadores de alimentos, estabelecida pela Resolução RDC 275/2002 (BRASIL, 2002), como parâmetro de avaliação dos resultados dos blocos de avaliação do checklist utilizado neste estudo.

Quando os estabelecimentos foram categorizados conforme proposto pela RDC 275/2002, cinco (41,7\%) classificaram-se no Grupo 3, com média de 45,7\% de atendimento aos itens; seis (50\%) no Grupo 2, com média de 60,4\% de atendimento aos itens; e apenas um estabelecimento (8,3\%) no Grupo 1 , com 90,5\% de atendimento aos itens do checklist. Na Tabela 3 podem ser observadas as classificações individuais dos estabelecimentos avaliados de acordo com a RDC 275/2002 (Grupo 1 - 76 a 100\% de atendimento dos itens; Grupo 2 - 51 a 75\% de atendimento dos itens; Grupo 3 - 0 a 50\% de atendimento dos itens). 
TABELA 3 - Conformidades e classificação dos estabelecimentos de acordo com a legislação.

\begin{tabular}{ccc}
\hline Estabelecimento & $\begin{array}{c}\text { \% itens conforme } \\
\text { Portaria 78/2009 }\end{array}$ & $\begin{array}{c}\text { Classificação do } \\
\text { Estabelecimento } \\
\text { RDC 275/2002 }\end{array}$ \\
\hline 1 & Bares & Grupo 2 \\
\hline 2 & 51,1 & Grupo 3 \\
\hline 1 & 50,4 & \\
\hline 2 & Pizzarias & Grupo 3 \\
\hline 3 & 49,6 & Grupo 2 \\
\hline 1 & 55,8 & Grupo 2 \\
\hline 2 & 62,3 & Grupo 3 \\
\hline 3 & Restaurantes & Grupo 2 \\
\hline 4 & 43,7 & Grupo 2 \\
\hline 5 & 68,9 & Grupo 2 \\
\hline 6 & 69 & Grupo 3 \\
\hline 7 & 55 & Grupo 3 \\
\hline & 38,2 & Grupo 1 \\
\hline
\end{tabular}

Fonte: elaborada pelo próprio autor.

Diante de tais resultados é possível destacar a necessidade de melhorias nos processos de BPM, para que haja maior segurança nos produtos elaborados aos consumidores. A exceção observada é em relação ao restaurante 7 , que se enquadra no Grupo 1, uma vez que apresentou 90,5\% de adequação à legislação vigente. No estudo de Blanger, Nunes e Sant'Anna (2017) que avaliaram as adequações à Portaria 78/2009 da SES/RS em treze estabelecimentos do tipo self-service na região do Vale do Taquari, apenas um estabelecimento avaliado classificou-se no Grupo 1, e, assim como observado em nosso estudo, a maioria dos estabelecimentos avaliados se enquadrou no Grupo 2.

Segundo a RDC 275/2002, os itens mais bem classificados seriam aqueles com 76\% de atendimento. Dessa forma, podemos inferir, através da Figura 2, que os blocos mais bem avaliados foram: o bloco 3, com questões referentes ao controle integrado de pragas, que apresentou 90,5\% de conformidade; 0 
bloco 4, com questões sobre o abastecimento de água, demonstrando 84,5\% de conformidade; e o bloco 10, com questões relacionadas à exposição do alimento preparado ao consumo, com 83,4\% de conformidade. No estudo de Blanger, Nunes e Sant'Anna (2017) os blocos de avaliação com maior percentual de conformidades também corresponderam ao controle de pragas e ao abastecimento de água, estando 100\% dos dados de acordo com a legislação.

Todos os demais blocos de avaliação ficaram abaixo do limite estabelecido pela legislação, de 76 a 100\%, com destaque para os blocos 11 - documentação e registro e 12 - responsabilidade, que tiveram os piores desempenhos, com 25\% e 6,3\% das questões em conformidade, respectivamente. Esses dados provavelmente são explicados pela não exigência de responsável técnico (RT), com formação na área, para liberação de alvará sanitário, já que tal profissional poderia contribuir na adequação dos itens. Cabe destacar, ainda, que o percentual de conformidades nos blocos de avaliação 6 - manipuladores e 8 - preparação do alimento ficou abaixo de 50\%.

Os percentuais de adequação dos estabelecimentos foram comparados por tipo de atividade, havendo grande discrepância dos resultados na maioria dos blocos de avaliação (Figura 2). 
FIGURA 2 - Percentuais gerais de conformidades conforme blocos de avaliação.

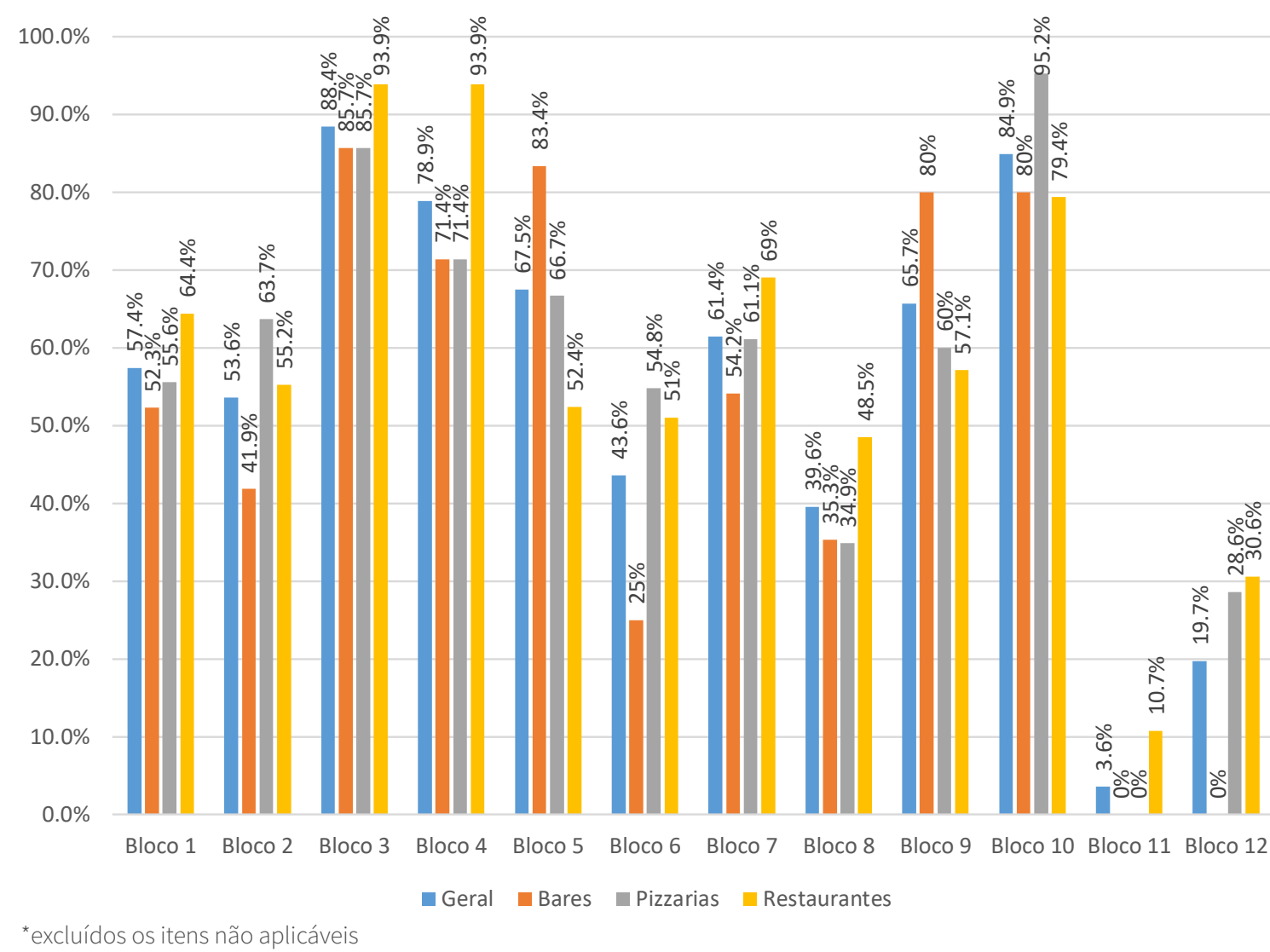

Bloco 1 - Edificação, Instalações, Equipamentos, Móveis e Utensílios; Bloco 2 - Higienização de Instalações, Equipamentos, Móveis e Utensílios; Bloco 3 - Controle Integrado de Pragas; Bloco 4 - Abastecimento de Água; Bloco 5 - Manejo de Resíduos; Bloco 6 - Manipuladores; Bloco 7 - Matérias-primas, Ingredientes e Embalagens; Bloco 8 - Preparação do Alimento; Bloco 9 - Armazenamento e Transporte do Alimento Preparado; Bloco 10 - Exposição ao Consumo do Alimento Preparado; Bloco 11 - Documentação e Registro; Bloco 12 - Responsabilidade.

Fonte: elaborada pelo próprio autor.

É preocupante o percentual de não adequações, principalmente nos blocos de avaliação 11 e 12, em que 91,6\% dos estabelecimentos avaliados não possuíam Manual de Boas Práticas (MBP), nem Procedimentos Operacionais Padronizados (POP). Isso, mais uma vez, reflete a falta de responsáveis técnicos com formação na área nos estabelecimentos, bem como de capacitação, já que, mesmo no estabelecimento que contava com responsável, não existiam MBP e POP. Verificou-se que 50\% dos estabelecimentos não dispunham de curso de capacitação para as atividades de manipulação; em 75\% dos estabelecimentos, o responsável técnico, quando existente, não 
fazia cursos de atualização periódicos; em 91,6\% dos estabelecimentos, não era realizado treinamento mínimo anual de atualização em boas práticas; e nenhum estabelecimento detinha comprovação do treinamento da equipe de manipuladores.

Em nenhum dos estabelecimentos havia registros das operações de limpeza e/ou desinfecção das instalações e equipamentos. Nenhum estabelecimento possuía uniforme diferenciado para os colaboradores que trabalhavam na higienização das instalações. Na maioria dos estabelecimentos, a limpeza dos panos e a desinfecção das esponjas não seguia o preconizado pela legislação estadual.

A legislação, de 2004, estabelece que os serviços de alimentação devem dispor de MBP e de POP, e que devem ser implantados minimamente os POP sobre higienização de instalações, equipamentos e móveis; controle integrado de vetores e pragas urbanas; higienização do reservatório; e higiene e saúde dos manipuladores (BRASIL, 2004). Dos estabelecimentos pesquisados, apenas um afirmou estar em processo de implantação.

A referida legislação ainda define que o responsável pelas atividades de manipulação dos alimentos deve ser comprovadamente submetido a curso de capacitação que aborde, no mínimo, os seguintes temas: contaminantes alimentares; DTA; manipulação higiênica dos alimentos; e boas práticas (BRASIL, 2004). No estado do Rio Grande do Sul, a SES definiu que o curso de capacitação deve ter no mínimo 16 (dezesseis) horas, com validade de três anos (RIO GRANDE DO SUL, 2009).

A falta de capacitação reflete em outro ponto importante, que é o controle de tempo/temperatura, crucial na produção de alimentos. Neste estudo, verificou-se que em 91,7\% dos estabelecimentos não havia instrumentos ou equipamentos de medição críticos para a segurança dos alimentos, tais como termômetros. Segundo o Codex Alimentarius, o controle inadequado da temperatura é uma das causas mais comuns de ocorrência de DTA. Os 
controles incluem tempo e temperatura de cocção, resfriamento, processamento e armazenamento, recomendando-se a implantação de sistemas que garantam esse controle eficaz da temperatura, quando for essencial para a segurança e a adequação dos alimentos (OPAS, 2006). A RDC 216/2004 e a Portaria 78/2009 indicam as temperaturas mínimas a serem atingidas na cocção dos alimentos, o tempo de exposição e de resfriamento e as temperaturas de congelamento.

Em decorrência dessa falta de equipamentos, nenhum dos estabelecimentos pesquisados estava em conformidade com a legislação estadual quanto à aferição da temperatura no recebimento de matérias-primas e ingredientes. O regramento em questão estabelece que alimentos congelados devem estar em temperaturas menores ou iguais a - $12^{\circ} \mathrm{C}$, ou conforme rotulagem do fabricante, e que os refrigerados devem estar em temperatura igual ou inferior a $7^{\circ} \mathrm{C}$, ou conforme rotulagem (RIO GRANDE DO SUL, 2009). Quanto à temperatura de matérias-primas, ingredientes e produtos industrializados armazenados, a legislação gaúcha fixa valor igual ou inferior a - $18^{\circ} \mathrm{C}$ para alimentos congelados e inferior a $5^{\circ} \mathrm{C}$ para refrigerados (RIO GRANDE DO SUL, 2009). Nesse quesito, o percentual de estabelecimentos em desconformidade com as normas estaduais foi de 83,3\%. Ainda, constatou-se que 75\% dos estabelecimentos não respeitavam o tratamento térmico de no mínimo $70^{\circ} \mathrm{C}$ em todas as partes do alimento durante a cocção e que 83,3\% não garantiam as combinações de tempo e temperatura, a fim de assegurar a qualidade higiênico-sanitária dos alimentos. Cabe destacar que em 50\% dos estabelecimentos não eram monitoradas, registradas ou tomadas medidas de ação corretiva da temperatura de conservação a quente.

Na produção de alimentos, a recepção da matéria-prima é um ponto de controle, e tanto a seleção dos fornecedores quanto a conferência dos produtos durante o seu recebimento e armazenamento constituem exigências legais 
que contribuem para a garantia da qualidade e da inocuidade do produto final (CARDOSO et al., 2010).

Ainda, como pontos de não conformidade comuns entre os estabelecimentos, observou-se a ausência, em 50\% deles, de portas com fechamento automático, coletores de resíduos com acionamento sem contato manual e torneiras de fechamento automático. Em 75\% dos estabelecimentos não havia manutenção programada e periódica dos equipamentos e utensílios. Nenhum realizava calibração, tampouco tinha registros de manutenção e/ou calibração.

O abastecimento de água apresentou 84,5\% de conformidade, possivelmente porser o abastecimento do município realizado pela Companhia Riograndense de Saneamento (Corsan), que atende às exigências da potabilidade da água fornecida aos consumidores. Porém, em 50\% dos estabelecimentos não foram apresentados registros que comprovassem a higienização do reservatório de água. As legislações brasileira e estadual orientam que o reservatório de água deve ser higienizado no mínimo a cada seis meses (BRASIL, 2004; RIO GRANDE DO SUL, 2009).

Quanto aos manipuladores, pôde-se observar que a higiene dos colaboradores não era verificada diariamente em $83,3 \%$ dos estabelecimentos. Entre as não conformidades a serem destacadas nesse bloco de avaliação estão o uniforme, que não segue a recomendação de cor (clara); o asseio corporal, como uso de barba e adornos; assim como o hábito de falar, assobiar, espirrar, tossir, comer e de manusear dinheiro pelos manipuladores de alimentos.

Em relação ao preparo, em 66,7\% dos estabelecimentos não se adotavam medidas com o fim de minimizar o risco de contaminação cruzada, tendo-se verificado, inclusive, que perecíveis ficavam expostos por mais de trinta minutos à temperatura ambiente em $83,3 \%$ dos casos. Em 75\% dos estabelecimentos os hortifrutigranjeiros não seguiam os critérios de higienização, que incluem a seleção, a lavagem com água potável, a desinfecção com cloro e o enxágue 
final. Também não dispunham de separação física de área suja e área limpa para a higienização desses legumes, hortaliças e frutas.

Metade dos estabelecimentos não seguiam as orientações da legislação referentes ao uso de ovos. Segundo a Portaria 78/2009, os ovos devem ser utilizados quando estiverem limpos, íntegros e com registro no órgão competente, assim como dentro do prazo de validade, com conservação e armazenamento que não propiciem contaminação cruzada e respeitem as indicações da rotulagem; devem ser higienizados com água potável corrente, imediatamente antes do uso, quando apresentam sujidades visíveis; ovos crus não devem ser utilizados em preparações e servidos aos clientes; os alimentos devem ser preparados somente com ovos pasteurizados, desidratados ou tratados termicamente, assegurando sua inocuidade; quando submetidos à cocção ou fritura, devem apresentar toda a gema dura. O documento orienta, também, que as embalagens dos ovos não podem ser reutilizadas para outros fins.

As mãos dos manipuladores são uma das principais ferramentas utilizadas no preparo de refeições, porém observa-se que ainda há predomínio de práticas inadequadas de higienização, propiciando-se a contaminação por microrganismos que favorecem o desenvolvimento de DTA (SILVA et al., 2012). Durante as etapas de pré-preparo e preparo, os alimentos são expostos a riscos de contaminação por microrganismos, que pode estar relacionada a práticas de manipulação impróprias e se dar por meio da boca, pele, cabelos e, principalmente, mãos e unhas. Há, também, a contaminação cruzada, provocada quando alimentos prontos para o consumo são manipulados próximo a alimentos crus ou no mesmo local destes, por exemplo (CUNHA NETO; ROSA, 2014).

Dentre os microrganismos envolvidos em toxinfecções alimentares, podemos destacar a Escherichia coli, que indica contaminação fecal; Staphylococcus aureus, que está presente na microbiota humana e contamina alimentos por 
secreções nasais; e o Bacillus cereus, indicador de contaminação ambiental, originada durante o manuseio e processamento. Destaca-se que a contaminação dos alimentos por Bacillus cereus e E. coli acontece principalmente por meio de fezes e água contaminadas (MURRAY; ROSENTHAL; PFALLER, 2009).

A Salmonella sp. tem como principal reservatório natural o homem, e muitos alimentos podem ser contaminados com essa bactéria, especialmente carnes, ovos, leite e derivados (RUBIN et al., 2012). A manipulação de alimentos por colaboradores portadores de Salmonella pode causar grandes surtos alimentares.

Este estudo investigou o atendimento dos itens constantes na legislação do estado do Rio Grande do Sul quanto à segurança na produção de alimentos, sendo observado grande percentual de não adequações à legislação. Todos os blocos de avaliação devem receber atenção por parte dos estabelecimentos de alimentação, com destaque para documentação e registro, responsabilidade, manipuladores e preparação do alimento, buscando-se a correção de todas as não conformidades observadas.

\section{Considerações Finais}

Através deste estudo, que propôs analisar a adoção e adequação das BPM em serviços de alimentação no município de Santa Rosa (RS), observou-se um alto percentual de não conformidades a partir da aplicação do checklist proposto pela Portaria 78/2009 da SES/RS.

Quando analisados de forma conjunta, os resultados deste estudo apontam para o não atendimento à legislação em 37,7\% dos itens, indicando possibilidade de riscos à saúde dos consumidores. O não atendimento às normas estabelecidas pelas legislações nacional e estadual contribui para uma 
baixa qualidade higiênico-sanitária dos alimentos produzidos, favorecendo a ocorrência de DTAs.

Na avaliação por blocos, os aspectos que mais contribuíram para o baixo desempenho compreenderam aqueles referentes à documentação e registro, responsabilidade, manipuladores e preparação do alimento. Considerando o alto grau de não conformidades constatadas, sugere-se investimentos por parte dos estabelecimentos na adequação às exigências da legislação, com o objetivo de melhorar a qualidade dos serviços e produtos, garantindo segurança do ponto de vista alimentar aos seus consumidores.

\section{Referências}

AKUTSU, R.C.; BOTELHO, R.A.; CAMARGO, E.B.; SÁVIO, K.E.O.; ARAÚJO, W.C. Adequação das boas práticas de fabricação em serviços de alimentação. Revista de Nutrição, Campinas, v.18, n.3, p.419-427, mai./jun., 2005.

BLANGER, L.D.; NUNES, M.R.S.; SANT’ANNA, V. Avaliação das Condições Higiênicosanitárias dos Serviços de Alimentação com Self-service de Encantado - RS. Rev. Elet. Cient. UERGS, Porto Alegre, v.3, n.1, p.194-214, 2017.

BRASIL. Ministério da Saúde. Agência Nacional de Vigilância Sanitária. Resolução de Diretoria Colegiada - RDC 275 de 21 de outubro de 2002. Dispõe sobre o Regulamento Técnico de Procedimentos Operacionais Padronizados aplicados aos Estabelecimentos Produtores/Industrializadores de Alimentos e a Lista de Verificação das Boas Práticas de Fabricação em Estabelecimentos Produtores/ Industrializadores de Alimentos. Brasília, DF: Diário Oficial da União n² 206, de 23 de outubro de 2002. Disponível em: http://portal.anvisa.gov.br/documents/10181/2718376/RDC_275_2002_COMP. pdf/fce9dac0-ae57-4de2-8cf9-e286a383f254. Acesso em 12 ago. 2019.

BRASIL. Ministério da Saúde. Agência Nacional de Vigilância Sanitária. Resolução de Diretoria Colegiada - RDC 216, de 15 de setembro de 2004. Dispõe sobre Regulamento Técnico de Boas Práticas para Serviços de Alimentação. Diário Oficial da União, Brasil, 16 set. 2004. Disponível em: http://portal.anvisa.gov.br/documents/33916/388704/RESOLU\%25C3\%2587\%25C3\%25830-RDC\% 2BN\%2B216\%2BDE\%2B15\%2BDE\%2BSETEMBRO\%2BDE\%2B2004.pdf/23701496-925d-4d4d-99aa9d479b316c4b. Acesso em: 12 ago. 2019.

CARDOSO, R.C.V.; GÓES, J.Â.W.; ALMEIDA, R.C.C.; GUIMARÃES, A.G.; BARRETO, D.L.; SILVA, S.A.; FIGUEIREDO, K.V.N.A.; VIDAL JÚNIOR, P.O.; SILVA, E.O.; HUTTNER, L.B. Programa nacional de alimentação escolar: há segurança na produção de alimentos em escolas de Salvador-BA. Rev. Nutr., Campinas, v.23, n.5, p.801-811, 2010. 
CUNHA NETO, A.; ROSA, O.O. Determinação de microrganismos indicadores de condições higiênicas sanitárias nas mãos de manipuladores de alimentos. Revista Brasileira de Tecnologia Agroindustrial, v.8, n.1, p. 1251-1261, 2013.

GERMANO, P.M.L.; GERMANO, M.I.S. Higiene e vigilância sanitária de alimentos. 4. ed. Barueri-SP: Manole, 2011.

GIRELLI, A.; KOLCHINSKI, E.M.; BIONDO, E.; SANT’ANNA, V. Análise da Aplicação das Boas Práticas de Fabricação nas Agroindústrias Familiares do Arranjo Produtivo Local do Vale do Taquari. Rev. Elet. Cient. UERGS, Porto Alegre, v.1, n.1, p.50-57, 2015.

INSTITUTO FOODSERVICE BRASIL. Disponível em: <http://www.institutofoodservicebrasil.org.br/> Acesso em: 12 jun.19.

MURRAY. PR.; ROSENTHAL, K.S.; PFALLER, M.A. Microbiologia médica. Rio de Janeiro: Elsevier, 2009. OLIVEIRA, A.B.A.; PAULA, C.M.D. de; CAPALONGA, R.; CARDOSO, M.R.I.; TONDO, E.C. Doenças transmitidas por alimentos, principais agentes etiológicos e aspectos gerais: uma revisão. Revista HCPA, Porto Alegre, v.30, n.3, p. 279-285, 2010.

OPAS - ORGANIZAÇÃO PAN-AMERICANA DA SAÚDE; Agência Nacional de Vigilância Sanitária - ANVISA; Food and Agriculture Organization of the United Nations - FAO. Codex Alimentarius. Higiene dos Alimentos - Textos Básicos. Brasília: OPAS, 2006.

POERNER, N.; RODRIGUES, E.; PALHANO, A.L.; FIORENTINI, Â.M. Avaliação das condições higiênico-sanitárias em serviços de alimentação. Rev. Inst. Adolfo Lutz, São Paulo, v.68, n.3, p.399-405, 2009.

RIO GRANDE DO SUL. Secretária da Saúde. Portaria n 78 de 30 de janeiro de 2009. Aprova a Lista de Verificação em Boas Práticas para Serviços de Alimentação, aprova Normas para Cursos de Capacitação em Boas Práticas para Serviços de Alimentação e dá outras providências. Diário Oficial, Porto Alegre, 30 jan. 2009. p.35-40. Disponível em: http://www.tramandai.rs.gov.br/download/ portaria_estadual_078_2009.pdf. Acesso em 12 ago. 2018.

SANTOS, M.O.B.; RANGEL, V.P.; AZEREDO, D.P. Adequação de restaurantes comerciais às boas práticas. Revista Higiene Alimentar, São Paulo, v.24, n.90/91, p.44-9, 2010.

SILVA, E.A. Manual de Controle Higiênico-Sanitário em Serviços de Alimentação. $6^{a}$ ed. São Paulo: Varella, 2005.

SILVA, J. L.L.; MACHADO, E.A.; COSTA, F.S.; ABREU, L.T.A.; TAVEIRA, R.P.C.; DINIZ, M.I.G. Conhecendo as técnicas de higienização das mãos descritas na literatura: refletindo sobre os pontos críticos. Revista Brasileira de Pesquisa em Saúde, v.14, n.1, p.81-93, 2012. 